\title{
A Survey on Chemical Use among Household Community Product Enterprises Producing Cosmetics and Hazardous Substances in Nonthaburi Province, Thailand
}

\author{
Sarisak Soontornchai \\ School of Health Science, Sukhothai Thammathirat Open University, Nonthaburi 11120, Thailand
}

\begin{abstract}
How to cite this paper: Soontornchai, $S$ (2018). A Survey on Chemical Use among Household Community Product Enterprises Producing Cosmetics and Hazardous Substances in Nonthaburi Province, Thailand. The Educational Review, USA, 2(7), 379-385. http://dx.doi.org/10.26855/er.2018.07.002
\end{abstract}

Corresponding author: Sarisak Soontornchai, D.Sc., School of Health Science, Sukhothai Thammathirat Open University, Nonthaburi 11120, Thailand.

\section{Abstract}

Since the safety of chemicals that are used by community enterprises is a concern in Thailand, this research was undertaken to examine the use of such chemicals especially in producing cosmetics and hazardous substances which are under controlled of the Office of Food and Drug Administration in Nonthaburi province. This qualitative research was conducted in a sample of all 18 household community product entrepreneurs that had obtained a product quality certification according to the Community Product Standards in Nonthaburi province by in-depth interviews. The research instrument with content validity verified by 3 experts was an interview form on chemical use situation among household community product enterprises. Data were collected and then analyzed using descriptive statistics and content analysis. The findings revealed that most of the entrepreneurs were a single enterprise with an investment cost of 50,000-100,000 baht. They formulated their household community products with the knowledge gained from training courses. The chemicals used were selected with the advice from chemical experts and chemical traders. The production was carried out in their own residences with a separate area designated for this purpose; and the chemicals were kept in such an area as well and used according to the chemical pamphlets. They used personal protective equipment and discharging production waste into public sewers. They had no chemical information and hazard communication media in their production areas. The chemicals mainly used were detergents, surfactants, acids, and bases as well as herbs. They all could recognize aquatic environmental hazard pictograms and realize correct practices in terms of using separate production containers from cooking utensils, wearing gloves before handling any chemical, being concerned about chemical splash into their eyes, immediate cleaning a chemical spill, no smoking while working, and hand-washing after chemical handling and before eating.

\section{Keywords}

Globally Harmonized System of Classification and Labeling of Chemicals (GHS), Household Community Product Label, Community Product Standards, Cosmetics, Hazardous Substances, Thailand

\section{Introduction}

The Thai government has implemented an economic stimulus policy to reduce social inequalities by enhancing people's access 
to public services and creating career opportunities as well as stable income, which will also help resolve social conflicts and affliction. Thus, the Community Development Department has launched the One Tambon, One Product (OTOP) Scheme to assist communities or community enterprises to use local resources and wisdom in producing or developing local or community products. In this effort, the government has been providing all communities with new knowledge as well as financial and capacity building support in product management and marketing in order to connect community products towards domestic and international markets.

Tanyapuech (2010) reported that chemicals are generally used in producing community products especially cosmetics and hazardous substances. All such chemicals may have a negative impact on human heath and the environment in the community if the correct and appropriate use principles are ignored. According to the Thai Industrial Standard Institute (TISI), the household community products have been registered with the Office of Food and Drug Administration (FDA) and given a TISI quality mark, but their labeling has not followed the Globally Harmonized System of Classification and Labeling of Chemicals (GHS) of the United Nations for chemical safety management purposes. However, the FDA has been controlling household hazardous substances through GHS-based labeling as per the Ministry of Public Health's (MOPH's) Notification on Hazard Classification and Communication System of Hazardous Substances under the FDA's Responsibility of 2015, published in the Government Gazette on 19 March B.E. 2558 (2015), with the transition period of 1 year for single chemical substances and 5 years for chemical mixtures. The notification has been effective since 20 March 2016.

For the aforementioned reason, this survey research was conducted to examine the use of chemicals, detergents and surfactants, that were used for producing community products especially cosmetics and hazardous substances. Its aim was to obtain basic information to be used in developing guidelines for enhancing the capacity of local product entrepreneurs which would be provided by the FDA and relevant agencies. The study participants were all local entrepreneurs producing cosmetics and hazardous substance community products that had received the TISI quality mark in Nonthaburi province. Nonthaburi is one of the provinces that have a lot of such local producers in the country. The study results will be useful for relevant persons including local product producers and consumers to follow the chemical safety rules related to human health and the environment according to the GHS requirements.

\section{Objective}

To conduct a survey on the use of chemicals that were used by community product enterprises in producing cosmetics and hazardous substances, which had received the TISI quality mark in Nonthaburi province.

\section{Methodology}

As a pilot study, all 18 community product entrepreneurs who produced cosmetics and hazardous substances with the TISI quality mark in Nonthaburi province listed on the TISI website were in-depth interviewed on chemical use, using a questionnaire that contained four parts: part 1, respondent's personal information; part 2, general information on the production site; part 3, general information on the products; part 4, knowledge of chemicals; and part 5, handling of chemical substances. The content validity value of the instrument or item-objective congruence (IOC) index was 0.67 or over. Data obtained from in-depth interviews were recorded and analyzed using descriptive statistics and content analysis.

\section{Results}

\subsection{Basic Information of the Community Product Entrepreneurs}

Regarding the general information on the production venues, most of them $(72.2 \%)$ were single entrepreneurs and $61.1 \%$ pro- 
duced in a modified house, shop-house or townhouse. Of all the entrepreneurs, $44.4 \%$ had an initial investment of 50,000-100,000 baht, $61.1 \%$ obtained product formulas or production methods from a training course, and $38.9 \%$ selected chemical substances as per experts and chemical traders' advice.

Of all the production places at residences, $50 \%$ had a production area separate from the residential part; and $38.9 \%$ stored chemical substances in the production areas.

Of all production workers, $61.1 \%$ handled the chemicals as per the labels, the safety data sheet (SDS) and pamphlets from chemical traders, and 94.4\% wore personal protective equipment (PPE) while working. As for chemical waste disposal, 38.9\% of the production places discharged the liquid waste directly into pubic sewers and $83.3 \%$ had no chemical hazard communication signs in the workplaces. Most of the chemicals used were detergents, surfactants, acids, and bases as well as herbs.

\subsection{Chemical Knowledge}

According to the interview on chemical knowledge (Table 1), all entrepreneurs recognized the aquatic environmental hazard pictogram and had correct knowledge including (1) not only industrial chemicals have labels; (2) chemicals with the acute toxicity pictogram are more dangerous than those with the irritation pictogram; (3) the SDS is the document describing general information of chemicals, first-aid, emergency response, and hazard prevention; and (4) handling corrosives and eye irritants always needs a chemical resistant suit, gloves, goggles, and mask.

\subsection{Chemical Knowledge}

Regarding the handling of chemicals among the entrepreneurs (Table 2), they all had correct practices in terms of: (1) non-use of the same containers for cooking and production despite them being cleaned before using; (2) never having direct contact with chemicals while working; (3) never ignoring even with a little chemical splash into the eyes; (4) immediately cleaning up the floor with a chemical spill; (5) no smoking while working; and 6) cleaning hands after working and prior to eating.

\section{Discussions}

The study revealed that most of the community product entrepreneurs had the production in their residences but in a separate space. The chemicals used were kept in the production area. Normally, the production should take place in an area separated from chemical storage to prevent explosion from flammable chemicals, in accordance with the Manual on Chemical Safety Management for Small and Medium Enterprises (Department of Industrial Work, 2007).

The entrepreneurs stated that there were no chemical hazard risks for various reasons. For instance, they used small amounts of chemicals within the legal limit; their product formulas had been verified by the FDA; and they used chemicals as suggested by chemical traders. These concepts might not be correct as all chemicals must more or less have their own intrinsic hazardous properties. Therefore, working with chemicals has to be cautious and be warned of danger as risk communication in workplace according to Occupational and Safety Laws. Most chemicals used in the production process were detergents, surfactants, acids, and bases, which mainly cause skin sensitization and irritation. Tanyapuech and Soontornchai (2012) found that most of the main chemicals used in household community products were sodium linear alkyl benzene sulfonate and sodium lauryl ether sulfate as well as herbs.

All entrepreneurs had already known about the aquatic environmental hazard pictogram, which was clearly seen in their daily life. They all had correct knowledge that every chemical must have a label. The acute toxicity pictogram showed a high toxicity warning which was well-known by the workers and consumers about the adverse effects on their health. Most entrepreneurs stated that the SDS contains very useful chemical information on hazard, first-aid, emergency response, disposal, and hazard 
prevention.

Table 1. Chemical knowledge among household community product entrepreneurs.

\begin{tabular}{|c|c|}
\hline Chemical knowledge & $\begin{array}{l}\text { Number of correct re- } \\
\text { spondents }(\%)\end{array}$ \\
\hline zard statements & $14(77.78)$ \\
\hline Acute toxicity & $8(44.44)$ \\
\hline Corrosion & $6(33.33)$ \\
\hline Irritation & $18(100.00)$ \\
\hline Hazardous to aquatic environment & $12(66.67)$ \\
\hline $\begin{array}{l}\text { Chronic health hazards } \\
\text { 2) Chemical hazards consist of physical, health, and environmental hazards }\end{array}$ & $17(94.44)$ \\
\hline $\begin{array}{l}\text { 3) Chemical label is a crucial instrument in hazard communication to workers handling } \\
\text { chemicals }\end{array}$ & $16(88.89)$ \\
\hline 4) Only chemicals used in industrial plants must have a label. & $\begin{array}{l}18(100.00) \\
18(100.00)\end{array}$ \\
\hline $\begin{array}{l}\text { 6) The safety data sheet is a document containing general chemical information regarding } \\
\text { hazard, first-aid measures, emergency response, disposal considerations, hazard prevention, } \\
\text { etc. }\end{array}$ & $18(100.00)$ \\
\hline $\begin{array}{l}\text { 7) Correct first aid for chemical exposure to the eyes is rinsing cautiously with clean water for } \\
\text { several minutes. }\end{array}$ & $17(94.44)$ \\
\hline 8) Skin corrosion and irritation is classified as health hazards that occur on the skin. & $17(94.44)$ \\
\hline $\begin{array}{l}\text { 9) Chemicals with environmental hazards might be discharged into public sewers without any } \\
\text { dilution. }\end{array}$ & $15(83.33)$ \\
\hline $\begin{array}{l}\text { 10) While working with eye corrosive and irritating chemicals, the workers always wear } \\
\text { gloves, goggles, and a mask. }\end{array}$ & $18(100.00)$ \\
\hline 11) Acute toxicity of a chemical is caused by oral intake of the chemical only. & $16(88.89)$ \\
\hline $\begin{array}{l}\text { 12) Chemicals in bulk or heavy-weight containers should be placed below eye level or on the } \\
\text { floor. }\end{array}$ & $15(83.33)$ \\
\hline
\end{tabular}

However, more knowledge should be provided to the entrepreneurs as follows:

(1) Correct Waste Management or Disposal: Most of them discharged liquid waste from the production process directly into public sewers and dumped the solid waste into the municipal garbage truck. Some places had a grease trap or wastewater pond without any wastewater treatment before releasing it directly into the public sewer or being picked up by a certified waste dis- 
posal company. Generally, discharging chemical waste into the sea might drastically cause an environmental impact as the chemical waste would get into the food chain. Therefore, chemical waste has to be disposed of appropriately according to the chemical type. For example, contaminated cloth or paper must be kept in a closed container as chemical waste, not in a plastic tank as the tank might be dissolved. Therefore, using a wastewater pond might be useful for waste neutralization and sedimentation, in addition to other preliminary treatments such as filtration, incineration, and evaporation. Such chemical waste disposal has to conform with the Ministry of Industry's (MOI's) Notification on Disposal of Waste or Unused Materials (No. 2)

Table 2. Chemical handling practices of the entrepreneurs.

\begin{tabular}{|c|c|c|c|}
\hline \multirow{2}{*}{ Activity } & \multicolumn{3}{|c|}{ Practice frequency } \\
\hline & Always & Sometimes & Never \\
\hline $\begin{array}{l}\text { 1) You read and clearly understand the instructions on the chemical label } \\
\text { and pamphlet before using. }\end{array}$ & $\begin{array}{c}9 \\
(50.00)\end{array}$ & 8 & 1 \\
\hline $\begin{array}{l}\text { 2) You seriously use chemicals according to instructions on the label and } \\
\text { pamphlet. }\end{array}$ & $\begin{array}{c}15 \\
(83.33)\end{array}$ & 3 & - \\
\hline 3) You always participate in chemical safety knowledge transfer activities. & $\begin{array}{c}8 \\
(44.44)\end{array}$ & 6 & 2 \\
\hline 4) You pay attention to chemical details on the label and pamphlet. & $\begin{array}{c}15 \\
(83.33)\end{array}$ & 3 & - \\
\hline $\begin{array}{l}\text { 5) You use the same containers for cooking and production but with } \\
\text { cleaning before using. }\end{array}$ & - & - & $18(100.00)$ \\
\hline 6) You directly contact chemicals while working. & - & - & $18(100.00)$ \\
\hline 7) You dress up for preventing your body from chemical exposure. & $\begin{array}{c}17 \\
(94.44)\end{array}$ & 1 & - \\
\hline 8) You are more careful while handling chemicals. & $\begin{array}{c}17 \\
(94.44)\end{array}$ & 1 & - \\
\hline $\begin{array}{l}\text { 9) You are not concerned about a small amount of a chemical solution } \\
\text { splashed into the eyes. }\end{array}$ & - & - & $\begin{array}{c}18 \\
(100.00)\end{array}$ \\
\hline 10) You immediately clean spilled chemicals on the floor. & $\begin{array}{c}18 \\
(100.00)\end{array}$ & - & - \\
\hline $\begin{array}{l}\text { 11) You seriously keep chemicals as per the instructions on the labels and } \\
\text { pamphlets. }\end{array}$ & $\begin{array}{c}14 \\
(77.78)\end{array}$ & 3 & 1 \\
\hline $\begin{array}{l}\text { 12) You keep chemicals at a place separated from food storage and resi- } \\
\text { dential area. }\end{array}$ & $\begin{array}{c}17 \\
(94.44)\end{array}$ & - & 1 \\
\hline 13) You clean and check working area after working. & $\begin{array}{c}17 \\
(94.44)\end{array}$ & 1 & - \\
\hline 14) You bath immediately after chemical handling. & $\begin{array}{c}17 \\
(94.44)\end{array}$ & 1 & - \\
\hline $\begin{array}{l}\text { 15) You wear personal protective equipment such as gloves, mask, goggles } \\
\text { etc. while handling chemicals. }\end{array}$ & $\begin{array}{c}17 \\
(94.44)\end{array}$ & - & 1 \\
\hline 16) You have food and drinks near working area. & - & 1 & $\begin{array}{c}17 \\
(94.44)\end{array}$ \\
\hline 17) You smoke while working. & - & - & $\begin{array}{c}18 \\
(100.00)\end{array}$ \\
\hline 18) After working you clean your hands prior to eating. & $\begin{array}{c}18 \\
(100.00)\end{array}$ & - & - \\
\hline $\begin{array}{l}\text { 19) You segregate chemical containers and unused chemicals from general } \\
\text { waste. }\end{array}$ & $\begin{array}{c}15 \\
(83.33)\end{array}$ & 1 & 2 \\
\hline $\begin{array}{l}\text { 20) You throw unused chemicals into public sewers or bury them in the } \\
\text { ground. }\end{array}$ & 8 & - & $\begin{array}{c}10 \\
(55.56)\end{array}$ \\
\hline $\begin{array}{l}\text { 21) You drain wastewater from cleaning chemical contaminated containers } \\
\text { into the river or canal. }\end{array}$ & 2 & 1 & $\begin{array}{c}15 \\
(83.33)\end{array}$ \\
\hline $\begin{array}{l}\text { 22) You get rid of solid chemical waste into a municipal waste bin or send } \\
\text { it to a waste disposal company that has been certified by the Department of } \\
\text { Industrial Works (DIW). }\end{array}$ & $\begin{array}{c}14 \\
(77.78)\end{array}$ & - & 1 \\
\hline
\end{tabular}


of 2017. All remaining chemical in an opened plastic bag should be repackaged and resealed after use in order to prevent chemical spill. Used chemical containers are to be disposed of with a similar treatment method as for hazardous substances based on certain chemical intrinsic properties, according to the Manual for Chemical Safety Management for Small and Medium Enterprises (DIW, 2007).

(2) Chemical Hazard Communication: Almost all of the entrepreneurs had no chemical hazard communication media; and chemical hazards might afflict production workers. So, the Department of Industrial Works and the Department of Labour Protection and Welfare should play a key role in creating chemical safety procedures. Prasongngern, Soontornahai, and Kongpanich (2010) had also studied the GHS implementation among public and private sector agencies in Ayutthaya province and found that they still needed more GHS knowledge and support from relevant state agencies in such efforts.

This study also showed that the entrepreneurs were acquainted only with the acute toxicity and aquatic en vironmental hazard pictograms; so other pictograms should be further disseminated. They had rather good levels of chemical knowledge (83.3-100 \%) and chemical practices, but improvements were needed for habitually reading and understanding label advice and pamphlets before using chemicals (50\%), always participating in chemical handling activities (44.44\%), and never dumping unused chemicals into public sewers or burying them (55.56). That means they need more knowledge relating to the GHS and chemical safety management.

Most of them confirmed that they always wear personal protective equipment while handling corrosives and eye irritants. The researcher had also seen such practices while interviewing and visiting their real production areas. They had all correct practices on using different containers for eating and production, wearing gloves to avoid direct chemical contact, immediate cleaning up chemical spills, no smoking while working, and hand-washing after chemical handling and before eating.

\section{Recommendations}

It is recommended that relevant agencies should undertake the following:

(1) The FDA's Cosmetics and Hazardous Substance Control Bureau, which oversees the use of hazardous substances in households or for public health purposes, should (i) establish a network for disseminating the GHS knowledge, emphasizing toxicity and hazard pictograms, through Consumer Protection Sections under Provincial Public Health Offices and (ii) provide advice or consultation services for improving the production venues and product labeling for hazardous substances type 3 .

(2) The Thai Industrial Standard Institute (TISI) should promote the upgrading of community products according to the Co mmunity Product Standards, regarding chemical safety based on the GHS labeling requirements.

(3) The Department of Industrial Works should provide knowledge and consultation to the entrepreneurs on work area improvement, chemical waste disposal, and chemical hazard communication based on the GHS requirements in community product enterprises.

(4) Chemical traders should enhance the capacity of their sales and consultation staff to be knowledgeable of the GHS related to the chemicals used in household community product enterprises.

(5) Household community product entrepreneurs should handle chemicals cautiously during the preparation of household community products, especially cosmetics and hazardous substances, according to the SDS and GHS requirements.

\section{Acknowledgements}

I would like to express my sincere thanks to the Rattanakosinsompoch 200 Years Fund, Sukhothai Thammathirat Open University, for funding support for this research. Additionally, thanks are extended to all household community product entrepreneurs in Nonthaburi province for their participation throughout this survey. 


\section{References}

Department of Industrial Works. (2007). Manual on Chemical Safety Management for Small and Medium Enterprises. Thai-German Program Enterprise Competitiveness. Retrieved from php.diw.go.th/safety/wp-content/uploads/2015/01/safety kme.pdf .

Notification of Ministry of Industry on Disposal of Waste or Unused Materials (the 2nd Issue) (2017).

Notification of Ministry of Public Health on Classification and Hazard Communication of Hazardous Substances under the Responsibility of the Office of Food and Drug Administration (2015).

Notification of Ministry of Public Health on Label Hazardous Substance under the Responsibility of the Office of Food and Drug Administration (2015).

Office of Small and Medium Enterprises Promotion. Opportunity and Impact of OTOP and Entering into the ASEAN Economic Community. Accessed March 15, 2017. osthailand.nic.go.th/masterplan_area/userfiles/files/otop.pdf. (in Thai).

Prasonngurn, W., Soontornchai,S., \& Kongpanich, A. (2011). The Preparedness of the Private and Government Sectors to Implement Globally Harmonized System of Classification and Labelling of Chemicals in PraNakorn Si Ayutthaya Province. Thai Journal of Toxicology, 26(1), 14-28.

Tanyapuech, W. (2010). Globally Harmonized System of Classification and Labelling of Chemicals (GHS) and Environmental Management of Community Product Industry: A Case Study of Herb-Based Products in Koh Takien Village, Muang District, Chanthaburi Province. Master degree thesis of Industrial Environmental Management, School of Health Science, Sukhothai Thammathirat Open University.

Tanyapuech, W., \& Soontornchai, S. (2012). Globally Harmonized System of Classification and Labelling of Chemicals (GHS) and Environmental Management of Community Product Industry : A Case Study of Herb-Based Products in Koh Takien Village, Muang District, Chanthaburi Province. Thai Journal of Toxicology, 27(1), 29-42.

Thai Industrial Standards Institute. Community Product Standard. Accessed March 5, 2017. app.tisi.go.th/otop/otop.html. (in Thai).

Thai Industrial Standards Institute. Community Product Standard. Accessed March 10 , 2017. tcps.tisi.go.th/public/certificatelist.aspx ?province $=12 \ldots$ นนทบุรี. (in Thai).

United Nations. Globally Harmonized System of Classification and Labeling of Chemicals (GHS). 7th Revised ed. New York and Geneva, 2017. 